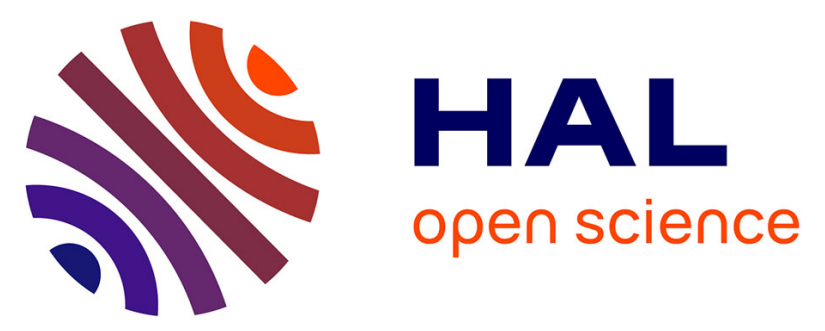

\title{
Comparison of additional costs for several replacement strategies of randomly ageing reinforced concrete pipes
} Franck Schoefs, X. Aduriz, Olivier Bernard, Bruno Capra

\section{To cite this version:}

Franck Schoefs, X. Aduriz, Olivier Bernard, Bruno Capra. Comparison of additional costs for several replacement strategies of randomly ageing reinforced concrete pipes. Computer-Aided Civil and Infrastructure Engineering, 2009, 24 (7), pp.492-508. 10.1111/j.1467-8667.2009.00603.x . hal-01005868

\section{HAL Id: hal-01005868 \\ https://hal.science/hal-01005868}

Submitted on 21 Feb 2017

HAL is a multi-disciplinary open access archive for the deposit and dissemination of scientific research documents, whether they are published or not. The documents may come from teaching and research institutions in France or abroad, or from public or private research centers.
L'archive ouverte pluridisciplinaire $\mathbf{H A L}$, est destinée au dépôt et à la diffusion de documents scientifiques de niveau recherche, publiés ou non, émanant des établissements d'enseignement et de recherche français ou étrangers, des laboratoires publics ou privés. 


\title{
Comparison of Additional Costs for Several Replacement Strategies of Randomly Ageing Reinforced Concrete Pipes
}

\author{
Franck Schoefs \& Xavier Aduriz \\ Nantes University (UNAM), 2 Rue de la Houssinière, 44322 Nantes Cedex 3, France
}

$\&$

Olivier Bernard

OXAND, 18 Avenue des Alpes, 1006 Lausanne, Switzerland

$\&$

Bruno Capra

OXAND, 49 Avenue Franklin Roosevelt, 77210 Avon/Fontainebleau, France

\begin{abstract}
One of the uses of reinforced concrete pipes $(R C P s)$ is the distribution of aggressive water in industrial systems, for example, in water-cooling systems of nuclear power plants. Some of them carry seawater and can deteriorate with time because of internal corrosion. Because of the low $\mathrm{O}_{2}$ content of aggressive water, slow corrosion is expected for such applications. If the RCPs are not periodically replaced, they will eventually fail. Replacement strategies for these pipes depend on (1) the risks associated with the failure of the water distribution network, and (2) the costs associated with replacing the pipes, including the removal of existing pipes, installation of new pipes, and associated production losses. Because of the lack of statistical data regarding $R C P$ failure, the development of a risk-based replacement strategy is not an easy task. This article demonstrates how predictive models for the evolution of the failure of RCPs and the associated consequences of failure can be used to
\end{abstract}

develop risk-based replacement strategies for RCPs. An application for the replacement strategies of a network modeled as a system consisting of 228 RCPs is presented as a case study. We focus on the assessment of the number of replaced components that governs the costs. The main objective of this article is to provide a theoretical approach for comparing replacement strategies, based on (1) the results of a reliability study, (2) the representation of the distributions of failed components (binomial distribution), and (3) the decision tree representation for replacement of RCPs. A focus on the scatter of the induced costs themselves is suggested to emphasize the financial risk.

\section{INTRODUCTION}

One of the uses of reinforced concrete pipes (RCPs) is the distribution of aggressive water in industrial systems. Some networks of RCPs are used, for example, 
in seawater transport (water cooling of nuclear power plants) and can deteriorate with time because of internal corrosion (Peter-Lazar et al., 2000). If the RCPs are not periodically replaced, they will eventually fail.

Inspection, maintenance, and repair (IMR) strategies for such water distribution networks are essentially based on pipe segment replacements. The goal of an optimal IMR strategy for RCP networks is to find when, where, and how to replace the network components. The optimal management strategy (OMS) depends on (1) the risks associated with the failure of the water distribution network, and (2) the costs associated with replacing the pipes, including the removal of existing pipes, installation of new pipes, and associated production losses (Luong and Fujiwara, 2002; Adey et al., 2003). The OMS should result in the highest reduction of risks and costs for owners of structures. This article does not provide optimization results but instead analyzes the sensitivity of a family of strategies to the lack of knowledge on the number of repairs.

Because of the lack of statistical data for RCP failure, the development of a risk-based replacement strategy is not an easy task. Some authors have addressed this issue in other industrial fields. Estes and Frangopol (2001) have used event tree representation to determine OMS of corroded reinforced bridges. Their approach can also be used to update the management strategy from the results of inspection. This article considers inspections at a constant interval. Note that methods based on genetic algorithms allow the consideration of the test interval as a random variable for optimization based on risk and cost criteria (Miyamoto et al., 2001; Martorell et al., 2004; Carlos et al., 2007). The Markov models are commonly used in management systems to model the deterioration of infrastructure assets, such as pipes (Micevski et al., 2002; Sheils et al., 2008; Breysse et al., 2009) and road bridges (Cambridge Systematics, 1997; Roelfstra, 2001). Semi-Markov models have been used to incorporate changes in failure mode that may occur with both time and the number of previous breaks (Li and Haimes, 1992). The Bayesian networks (De Melo and De J. Sanchez, 2005) can also be used and allow the updating of distribution, especially after inspection. Other alternatives consider nonprobabilistic approaches such as tolerance interval (Martorell et al., 2007a).

Because of the huge number of RCPs in the networks, the reduction of computation time is an important requirement. This article provides a theoretical approach to compare management strategies that meet this challenge, for the long-term horizon. It is based on (1) the results of a reliability study, (2) the representation of the distributions of failed components through a binomial distribution, and (3) the decision tree representation for RCP replacement. The main focus is on assessing the number of components to be replaced. In fact, this parameter directly affects the costs. When the network is composed of several types of components with several ageing laws, the question is which critical components should be replaced and when. To make the procedure more efficient, this number is computed as the number that maximizes the likelihood when considering the distribution of the numbers of failed components. Note that this methodology does not consider shortterm horizons and hydraulic considerations that are needed for sewer networks analysis (Dridi et al., 2008), specific metric taking into account pollutions (Nunes et al., 2007), or a multicriteria conception based on fuzzy logic (Sarma and Adeli, 2002).

The first part of this article presents the ageing model and the input of the study: the evolution of the probability of failure with time (i.e., the cumulative distribution function [cdf] of times to failure).

Following this, the methodology for assessing the binomial distribution of the number of failed components before replacement is developed. A network modeled as a series system is considered.

This approach is then extended to the case of mixed networks composed of replaced and nonreplaced components. A probabilistic updating is then suggested.

This article concludes with an illustration of a real network with two categories of components and a cost analysis that emphasizes the importance of decision aid tools with estimators based on the whole distribution of costs. It gives a refined analysis complementary to the usual minimization of a cost function (Li et al., 2007).

\section{PREDICTIVE MODELING AND RELIABILITY ANALYSIS OF CHLORIDE-INDUCED CORROSION OF RCP}

\subsection{Definition of RCP}

Figure 1 is a schematic of a RCP of a type typically used for industrial applications. Most of these RCPs consist of external and internal concrete layers separated by a cylindrical steel sheet. The external layer is usually reinforced in European countries and prestressed in Asia and the United States. The steel sheet placed between the two concrete layers plays a role in preventing leakage and in resisting the internal fluid pressure.

\subsection{Local corrosion criterion and reliability analysis}

Seawater contains chloride ions (typically $25-30 \mathrm{~g} / \mathrm{L}$ ), which are known to be aggressive against reinforced 


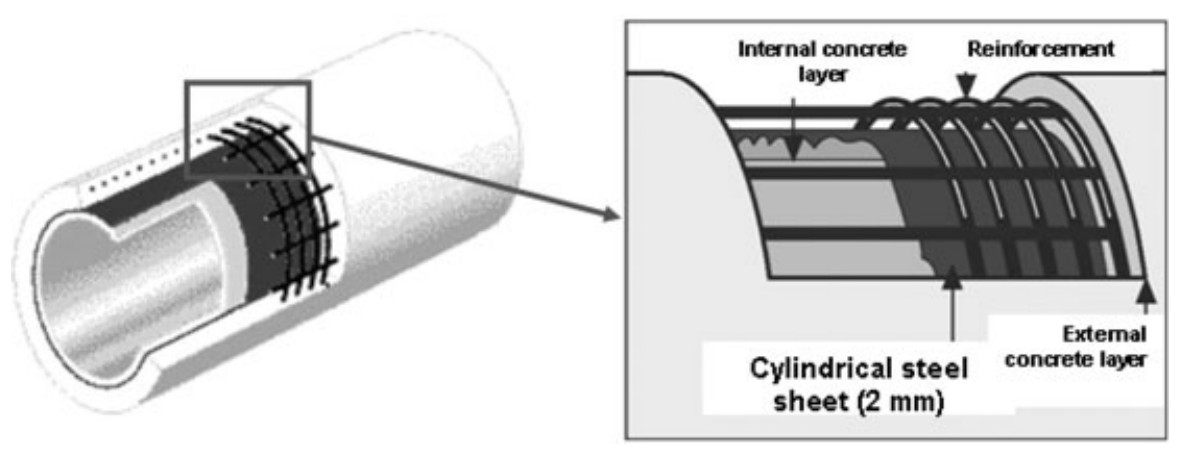

Fig. 1. Reinforced concrete pipe (RCP).

concrete. In the particular case of a seaside nuclear power station, RCPs are not buried but positioned on supports. They are $1 \mathrm{~m}$ in length. RCPs permanently contain seawater except during particular maintenance operations (change of a pipe, for example). It is observed that RCP deterioration with time is linked to internal corrosion (Peter-Lazar et al., 2000) due to the diffusion of chloride ions from seawater to the steel sheet via the internal layer of concrete.

A lot of work has been done on the modeling of the penetration of chloride ions into concrete, and models of varying levels of complexity have been developed: based on Fick's second law (Collepardi, 1997; Andrade, 2004; Nilsson, 2000; Frederiksen et al., 1997; PetreLazar et al., 2000) and flux equations (Tang, 1996; Frederiksen et al., 1997; Truc, 2000; Marchand et al., 2002). The software SIMEO ${ }^{\mathrm{TM}}$ (SIMEO $^{\mathrm{TM}}$, 2006) has been used to conduct a reliability study to determine the evolution of the probability of corrosion. This software is devoted to reliability computation and simulation in a user-friendly environment (selection of predefined probability density functions, etc.). Only the Monte Carlo algorithm has been used to obtain the results of this article.

The several stages of the corrosion process are described in Figure 2. The first phase of corrosion (Figure 2a) is characterized by chloride penetration from the pipe's internal surface to the steel sheet. This penetration process can be modeled as a stationary diffusion of the chloride brought to the pipe's internal surface by seawater. Taking $C_{s}$ as the chloride concentration on the internal pipe surface, $d$ the internal concrete cover, $C_{0}$ the initial chloride concentration of the concrete cover (in this article, $C_{0}=0$ ), and $D_{c}$ the chloride diffusion coefficient in concrete, the accumulated chloride concentration on the steel sheet's internal surface can be expressed as a function of time by
Equation (1) (Peter-Lazar et al., 2000):

$$
C(t)=C_{0}+\left(C_{s}-C_{0}\right)\left[1-\operatorname{erf}\left(\frac{d}{2 \sqrt{\alpha \eta D_{c} t}}\right)\right]
$$

where erf is the mathematical error function, and $\alpha$ and $\eta$ represent, respectively, the coefficients for the ion interaction and the ion-cement paste interaction in chloride transport in concrete:

$$
\alpha=1+\frac{1}{4 \cdot C_{s}} \quad \text { and } \quad \eta=\frac{1}{1+k}
$$

with $k$, the ion-cement paste interaction coefficient.

The estimated time for corrosion initiation is about 5 years according to available data.

When the accumulated chloride concentration $C(t)$ reaches a critical value, corrosion will initiate at the internal surface of the steel sheet (Figure 2b). This critical concentration is defined according to an empirical relationship between chloride concentration and hydroxyl ion concentration in concrete. The selected value in this article is $0.32 \mathrm{~mol} / \mathrm{L}$; it corresponds to a concentration $\left[\mathrm{Cl}^{-}\right] /\left[\mathrm{OH}^{-}\right]=0.6$ and a $\mathrm{pH}$ in the concrete of 13.5. Even if this concentration could be considered as random, even stochastic with time, no probabilistic model is available till now. Thus, for simplicity, it is considered as deterministic. Note that probabilistic modeling would modify the probability of failure with time and thus the cost analysis but not the ranking of the strategies. The rate of the loss of steel by corrosion is estimated, in our case, at $55 \mu \mathrm{m}$ per year according to the feedback on deteriorated pipes that have been investigated (pitting measurements). The rate of the loss of steel section depends on the corrosion current. By this modeling, the average rate of steel loss by chloride corrosion has been calculated for the whole service life of a RCP. In the following sections, it is consider as deterministic 


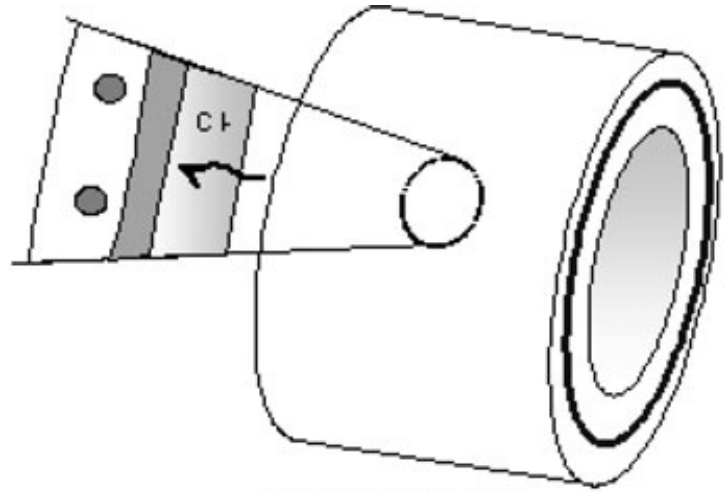

a) chloride migration

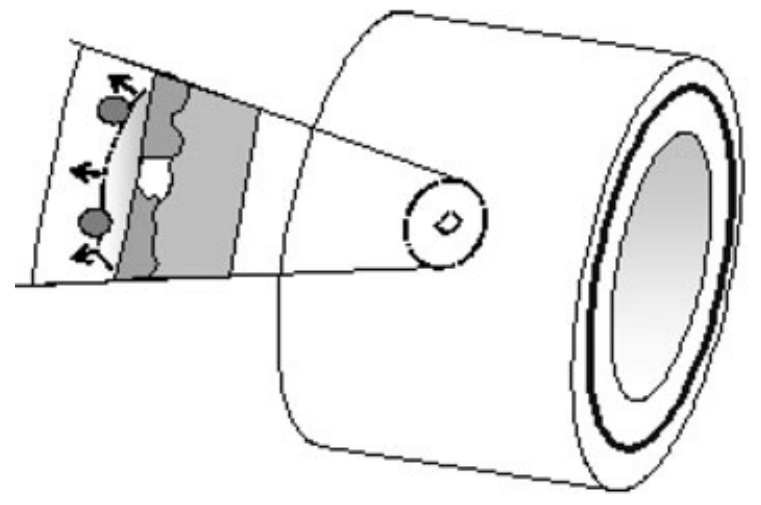

c) local hole, extemal concrete contamination by $\mathrm{Cl}$.

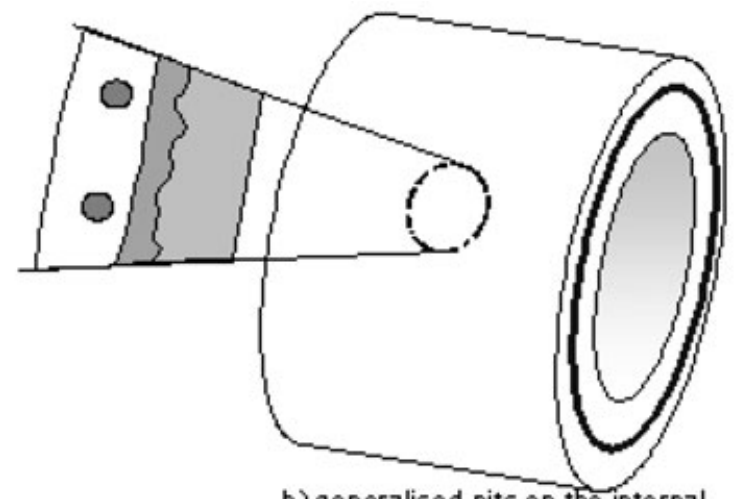

b) generalised pits on the internal side of steel core cyllinder

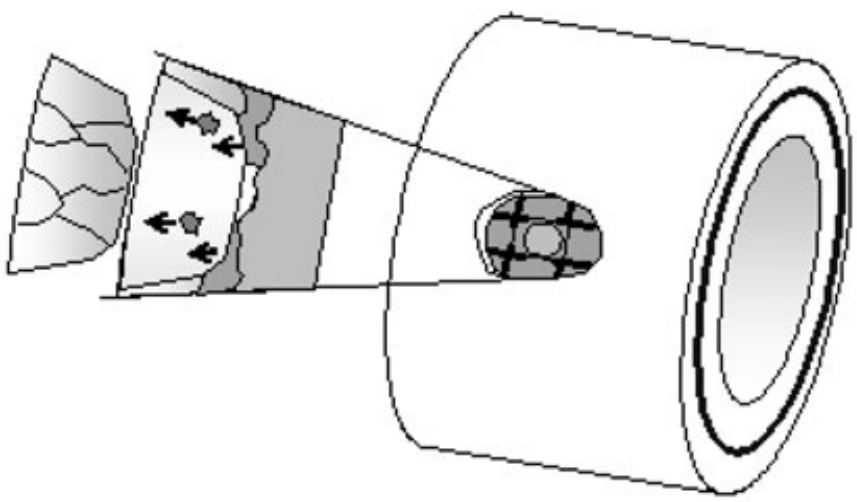

d) accelerated external corrosion, nonsaturated condition favourable

Fig. 2. Four stages of internal corrosion of RCP.

because its scatter in confined environment is very fair in comparison to the uncertainty propagation because of Equation (1). Once a local hole is present on the steel sheet (Figure 2c), chloride ions can migrate through the external layer of concrete and lead to the corrosion of the external side of the steel sheet. The process is then accelerated because of the nonsaturated condition of the concrete, which is favorable for corrosion development (Figure 2d).

For the purpose of a reliability analysis, probabilistic distributions are considered for modeling the scatter of the values of material parameters in the model, including the concrete cover thickness, the steel sheet thickness, and the corrosion rate. Table 1 summarizes the values and distribution laws taken for the simulations. At each time $t$, the generated samples allow the calculation of accumulated chloride concentration from Equation (1) through a crude Monte Carlo simulation. Note that the stochastic process is defined as a timedependent function of basic variables: it acts as an analytic transfer function of random variables, indexed with time, through the deterministic Equation (1). The limit state is built considering that a RCP is assumed to have failed when there is no more residual steel thickness. Thus, a RCP could have corroded but not yet failed. Taking a zero residual steel sheet thickness as the failure

Table 1

Deterministic or probabilistic modeling of variables for the reliability analysis

\begin{tabular}{|c|c|c|c|c|}
\hline Variable & Description (unit) & Law & Mean value & Standard deviation \\
\hline$C_{S}$ & Surface chloride concentration $(\mathrm{g} / \mathrm{L})$ & Deterministic & 20 & l \\
\hline$D_{C}$ & Chloride diffusion coefficient $\left(\mathrm{m}^{2} / \mathrm{s}\right)$ & Normal & $4.2 \cdot 10^{-12}$ & $2.2 \cdot 10^{-12}$ \\
\hline$k$ & Ion-cement paste interaction coefficient & Deterministic & 1.5 & 1 \\
\hline$d$ & Concrete cover $(\mathrm{mm})$ & Normal & 22.4 & 0.29 \\
\hline$e$ & Steel sheet thickness $(\mathrm{mm})$ & Deterministic & 2 & 1 \\
\hline
\end{tabular}




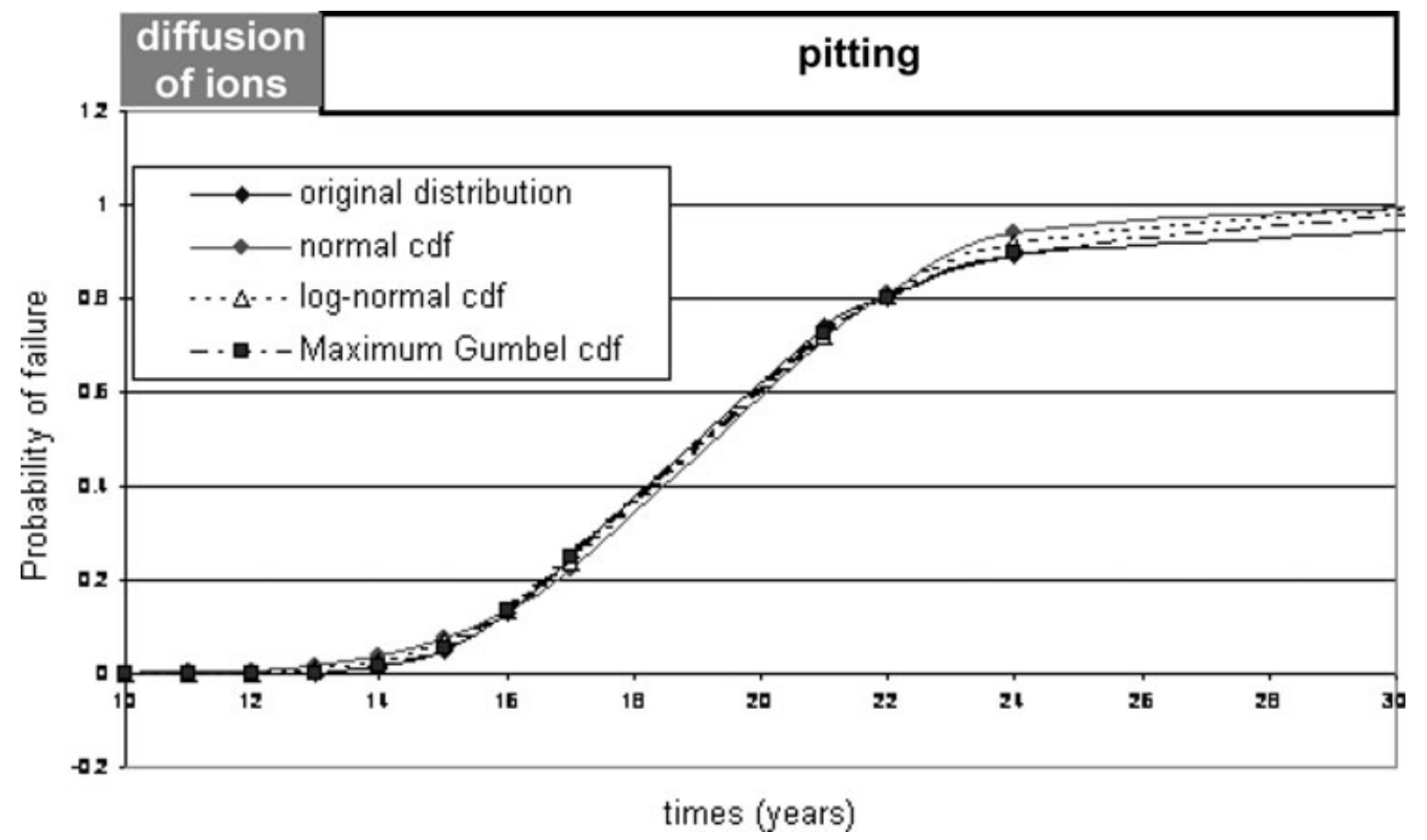

Fig. 3. Typical distribution of time to failure $(\varphi(t))$ of RCP and fitted cumulative distribution functions.

criterion, the time-dependent failure probability is calculated via a coarse Monte Carlo simulation method with 10,000 samples. The resulting distribution of time to failure is presented in Figure 3. We note that the diffusion of ions that leads to no failure with the selected limit state occurs in the first 10 years during which the probability of failure does not increase. We consider this curve as an input in our study. If another RCP is considered, the modeling of Table 1 must be changed. This evolution of the probability of failure describes a survival function. This function is least-square-fitted using several cdfs.

When comparing the plots of the cdf fitted to the original cdf, we observe that some functions (see lognormal, for instance) fit quite well during the early stages but diverge from the original distribution after 22 years. Note that this model of cdf can be convenient if the replacement strategy for failed pipes is frequent, in which case only the early stages of the cdf curve are considered. This point is discussed in more detail at the end of this article.

\section{STRUCTURAL ANALYSIS: THE CASE OF RCP NETWORK}

\subsection{Assessment of the failed components distribution in a network modeled as a series system}

From the input curve such as in Figure 3, the question is now to assess the number of failed components in a network before and after repair. Note that the representation of a structure as a combination of serial/parallel failure components is widely documented in the literature (Hendawi and Frangopol, 1994) and is a very useful formal representation for system analysis. An analogy with electronic systems can be made. Note that, in general, this is an approximate representation and may not be an exact depiction of the real physical form of the network. The considered RCP network is modeled as a series system composed of several categories of components, jointed together. This theoretical section of the article deals only with one category to clarify the approach. The final part of this article suggests an illustration with two categories. Several factors affect the initial state and thus the probability of failure:

- RCPs are manufactured by different companies, with different quality control processes; and

- the storage conditions (outside or inside, multilayers or single layers) and duration before installation vary between RCPs.

From the feedback of owners, we assume that joints between RCPs have a negligible probability of failure and isolate each RCP from those adjacent to it.

We assume that failures/nonfailures of each pipe segment are statistically independent events and the serial representation of the network is perfect. This assumption allows us to simplify the analysis and is conservative when analyzing series systems. Further studies are 
needed to quantify these factors and how they affect the heterogeneity of the network. Note that in that case the system probability of failure is given by:

$$
P_{f, s}(t)=1-\prod_{i=1}^{n}\left(1-P_{f, i}(t)\right)
$$

where $P_{f, i}(t)$ is the probability of failure of component $i$ at time $t$. In this study, the aim is not to compute the probability of failure but to assess the number of failed RCPs at time $t$. This allows determination of the number of repair or preventive replacements to be planned. All the RCPs of the network modeled as a series system are supposed to be in a similar state at time $t_{0}=0$. The expected number $m(t)$ of failed RCPs at time $t$ is expressed as follows:

$$
m(t)=n \times \varphi(t)
$$

where $n$ is the total number of RCPs.

Thus, the cumulative failure distribution functions $\varphi(t)$ of each component are the input of the problem (see Figure 3).

In what follows, the series representation is considered to be perfect: the failure of one component does not affect the probability of failure of neighboring components as well as the quality of the water flowing in the network.

\subsection{Approximation of the distribution of failed RCPs with a binomial distribution}

A distribution of failed RCPs is proposed at each time $t$ to determine the number of failed RCPs with a confidence level. By knowing $n$ (total number of RCPs) and $\varphi(t)$, we assume that the distribution of failed components follows a binomial distribution with parameter $n$ and probability $p(t)=\varphi(t)$. The use of such hazard functions in a time-dependent reliability analysis is covered in detail in Mori and Ellingwood (1994a). Under this assumption, the probability of having $k$ failed RCPs at time $t$ is given by the discrete probability distribution (Equation (4)):

$$
P_{f}(x=k, t)=\frac{n !}{k !(n-k) !} \varphi(t)^{k}(1-\varphi(t))^{(n-k)}
$$

We then define a binomial stochastic process. Note that the mean trajectory of this process is an increasing function with time and is not a stationary process: in particular, the first two probabilistic moments (mean and variance) are time-variant functions. For example, the variance equals $n p(1-p)$ : as $t$ tends to 0 or infinity, $p$ tends, respectively, to 0 or 1 , and the variance tends to 0 . Figure 4 illustrates four distributions obtained for $t=16,18,20$, and 22 years from the cumulative fail- ure distribution function presented in Figure 3. Among these four cases, the probability at " $t=20$ years" corresponds to the maximum value of the standard deviation and is obtained for a probability of RCP failure of 0.6 (see Figure 3). Note that this distribution is discrete and appears in the figure as continuous because of the high number of RCPs.

For the initial and final corrosion states, the number of failed RCPs is quite deterministic. It is because of the fact that the probability of failure describes a failure criterion with a binary response. Thus, the standard deviation is not increasing with time.

It is now possible to assess the number of failed RCPs with a confidence level of $5 \%$ or $95 \%$ from these distributions.

\section{PROBABILISTIC UPDATING AFTER REPAIR}

\subsection{Formal representation of maintenance strategies based on event tree}

Under the previous assumptions, the event tree representation is used to build maintenance strategies. This formal graphical scheme allows us to represent several paths for maintenance strategy — called scenariosrepresented by a branch that links the bounds of the decision "replace or don't replace" (Figure 5). In this case, the diagram is called a "decision tree," as it represents courses of action: either replacement or nonreplacement. It allows building several branches from the original branch of nonreplaced RCP until the reference period $t_{\text {end }}$ is reached. It has been used as a decision aid tool in the offshore industry and bridge maintenance planning (Faber and Sorensen, 2002). Note that imperfection in detection can be introduced too in the form of defect detectability function (Mori and Ellingwood, 1994a,b) or the probability of detection and probability of false alarm (Rouhan and Schoefs, 2003; Pakrashi et al., 2008; Schoefs, 2009). The cumulative failure distribution function of each component follows the time-dependent probability of failure given in Figure 3.

\subsection{Management strategy: Choice of the number of replaced RCPs at time $t$}

Over the last decade or so, several papers have covered this issue, including the role of inspection (Bjørnoy et al., 2001; Onofriou and Frangopol, 2002; Ritchie et al., 1998). In this article, only the date of replacement is considered as a maintenance parameter. The number of potential replaced RCPs at time $t$ is determined by the maximum probability of the distribution 


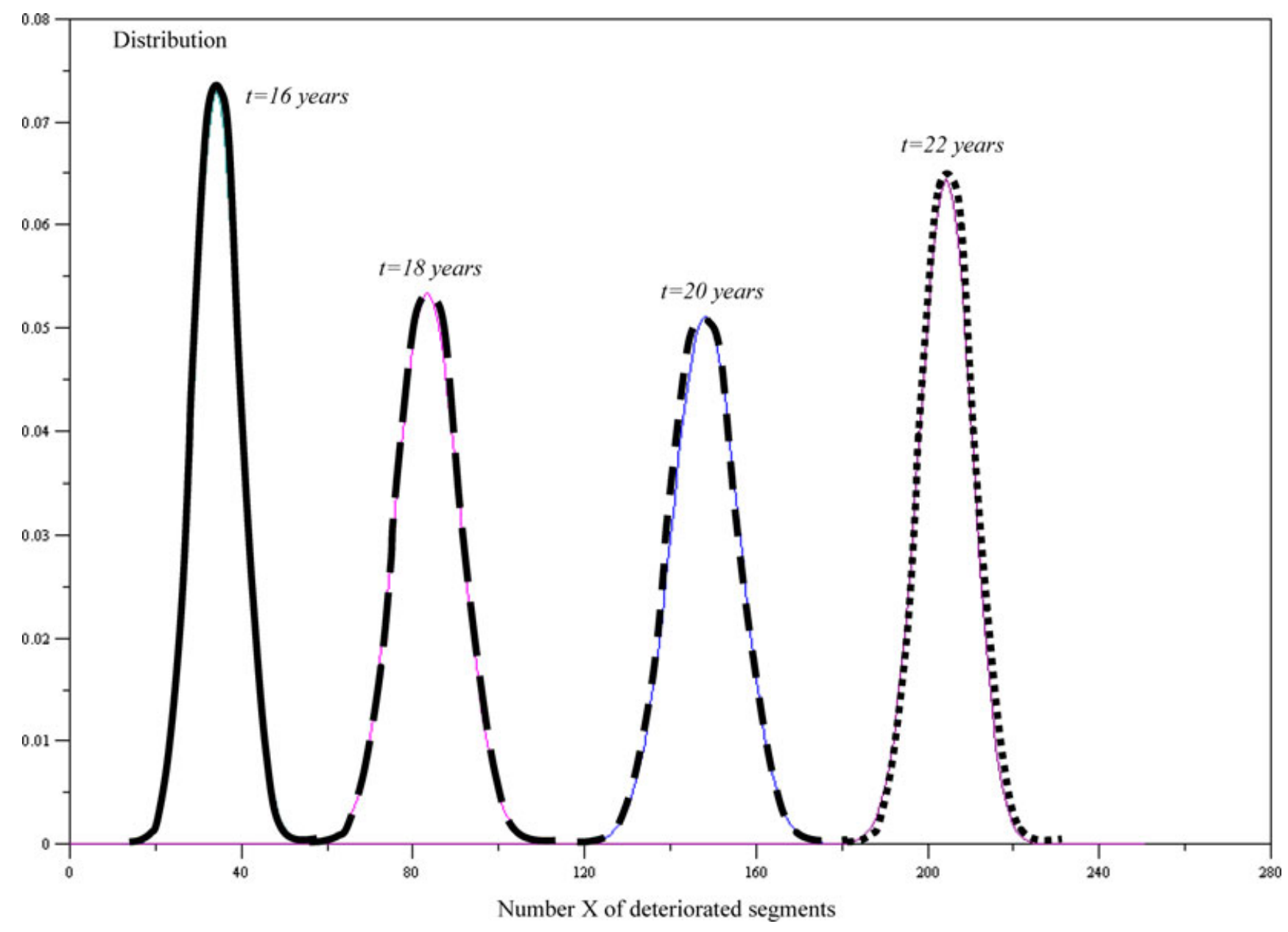

Fig. 4. Distribution of deteriorated segments at four times: $t=16,18,20$, and 22 years.

of the numbers of failed components at this time. This number is supposed to be given by an inspection of the network at time $t$. All the nonrepaired components are then supposed "as good as new." This is, of course, an assumption to simplify here the formulation of the updating. Thus, under this assumption, the method is consistent with the Bayesian theory.

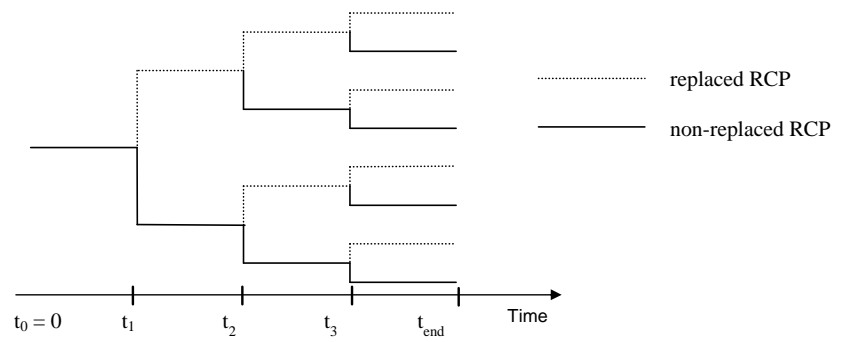

Fig. 5. Decision tree as graphical support to represent maintenance strategy.

\subsection{Distribution of the number of failed RCPs after one action $\left(t_{2}>t>t_{1}\right)$}

Once the number $m_{1}$ of replaced RCPs is selected, the accurate size of populations for replaced and nonreplaced $\left(n-m_{1}\right)$ RCPs at time $t$ is known. Thus, the probability distribution of the number of replaced RCPs is a binomial probability distribution with parameters $m_{1}$ and $p(t)=\varphi\left(t-t_{1}\right)$. Note that imperfect maintenance can be introduced at this step (Sánchez et al., 2007). The probability distribution of the number of remaining intact RCPs is determined in the same way using a binomial probability distribution with parameters $\left(n-m_{1}\right)$ and $p(t)=\frac{\varphi(t)-\varphi\left(t_{1}\right)}{1-\varphi\left(t_{1}\right)}$. For numerical simulations, it is important to mention that when $t$ reaches the lifetime of the RCPs, the expression of $p(t)$ becomes numerically undefined. Then, the result $\frac{\varphi(t)-\varphi\left(t_{1}\right)}{1-\varphi\left(t_{1}\right)} \underset{\infty}{\longrightarrow} 1$ is introduced $(\varphi(t)=1$ when $t$ tends to infinity).

The probability of the number of failed RCPs at each time $t \geq t_{1}$ and before the next action is obtained 
through a summation of products:

$$
P(X=x, t)=\sum_{i=0}^{x} P_{2}(X=i, t) \times P_{1}(X=x-i, t)
$$

where $P_{1}(X=x)$ is the probability to have $x$ nonreplaced RCPs at time $t_{1}$ that fail at time $t$, and $P_{2}(X=$ $x$ ) is the probability to have $x$ replaced RCPs at time $t_{1}$ that fail at time $t$.

\subsection{Distribution of the number of failed RCPs after $i$ actions, $\left(t>t_{i}\right)$}

There are $2^{i}$ populations that are described at time $t$ by only $(i+1)$ distributions because some of them are complementary. In the following equation, $m(i, j)$ is the number of RCPs of the branch $j$ after $i$ actions. These distributions are determined with the following step-bystep method:

- first, the distribution of the number of nonreplaced RCPs during the whole period $t$ is a binomial probability distribution with parameters:

$$
m\left(i, 2^{i}\right) \text { and } p(t)=\frac{\varphi\left(t-t_{0}\right)-\varphi\left(t_{i}-t_{0}\right)}{1-\varphi\left(t_{i}-t_{0}\right)}
$$

- second, the distribution of the number of nonreplaced RCPs at time $t_{i}$ but replaced at time $t_{k}(1 \leq$ $k \leq i-1)$ is a binomial probability distribution with parameters:

$$
\begin{aligned}
m(i, k) & =\sum_{j=0}^{2^{k-1}-1} m\left(i,\left(1+2^{j}\right) 2^{i-k}\right) \text { and } \\
p(t) & =\frac{\varphi\left(t-t_{k-1}\right)-\varphi\left(t_{i}-t_{k-1}\right)}{1-\varphi\left(t_{i}-t_{k-1}\right)}
\end{aligned}
$$

- finally, the distribution of the number of replaced RCPs at time $t_{i}$ is a binomial probability distribution with parameters:

$$
m(i, i+1)=\sum_{j=1}^{2^{i-1}} m\left(i, 2^{j}-1\right) \quad \text { and } \quad p(t)=\varphi\left(t-t_{i}\right)
$$

Then, an expansion of Equation (5) for any value of $i$ writes:

$$
P(X=x)=\sum_{a=0}^{x} P_{i+1}(X=a) \times \cdots \times \sum_{i=0}^{h} P_{3}(X=i)
$$

$$
\times \sum_{j=0}^{i} P_{2}(X=j) \times P_{1}(X=x-j-i)
$$

where $P_{1}(X=x)$ is the probability of having $x$ nonreplaced segments for any value of $t_{i}$ that fail at time $t$, $P_{k}(X=x)$ is the probability of having $x$ replaced segments at time $t_{k-1}(2 \leq k \leq i)$ that fail at time $t$, and $P_{i+1}(X=x)$ is the probability of having $x$ replaced segments at time $t_{i}$ that fail at time $t$.

This formalism is well adapted for linear algebra programming such as in SCILAB (SCILAB, 2007), which is an interactive system whose elementary element is a matrix that does not require any dimensioning. Thus, the explosion of cases of combinations because of the number of components to repair and the number of repairing dates does not pose a problem. Note that the number of actions is also reasonable and therefore makes the computation time convenient.

\section{ILLUSTRATION OF UPDATING ON A REAL RCP NETWORK}

\subsection{Input values, main assumptions, and maintenance strategy}

The study of the corrosion process in a real network lies in another curve for describing the evolution of the probability of failure with time than that shown in Figure 3. In fact, in the network selected for the application, we define two sets of RCPs with several behaviors:

- the RCPs located in the ordinary areas where internal corrosion is acting; and

- the RCPs located near bends or supports, called "singular" areas where an external corrosion mechanism is superimposed because of differential aeration conditions. This differential aeration takes place anytime when there is a step between concrete cover (supports and bend). The study of existing systems allowed the determination of an equivalent corrosion rate and a corresponding cumulative failure distribution function in this case.

Note that these curves differ from the one in Figure 3 because some parameters of the RCPs are different.

The network is composed of 90 RCPs located in singular areas and 138 located in ordinary areas. In both cases, RCP lifetime is about 60 years (probability of failure about $95 \%$ ). Figure 6 presents the distribution of time to failure. We observe that the RCPs in singular areas are subject to a faster increase of the probability of failure. Several cdfs are suitable; here, the log-normal cdf has been selected. 


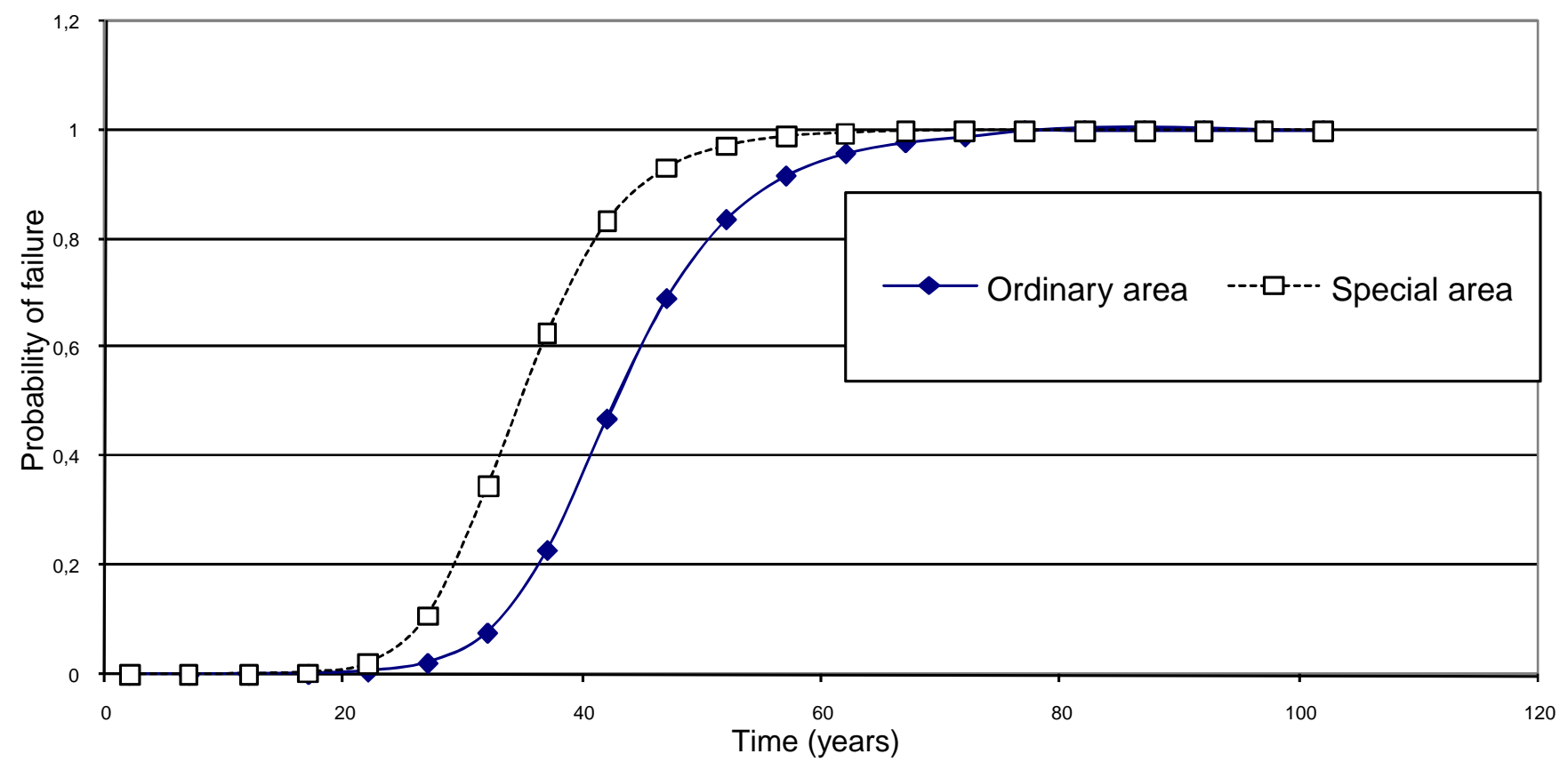

Fig. 6. Distribution of time to failure in ordinary and singular areas.

As mentioned at the beginning of this article, these curves are the input of the methodology.

The management strategy consists of the replacement of failed RCPs. Two types of strategies are then tested:

(1) the date and the number of actions are imposed; and

(2) the total number of failed RCPs is limited to an upper-bound value (threshold).

As presented before, the number of potentially replaced RCPs at time $t$ is still determined with the maximum likelihood of failed components at time $t$. It is supposed that the network was not repaired during the first 20 years. The following sections present the results obtained with the two types of strategies.

\subsection{Imposed dates of maintenance}

Typically, maintenance strategies of operators/owners do not include plans for replacement of RCPs before their guaranteed lifetime is up. Several guaranteed lifetimes are assumed here: 20, 25, 30, 35, and 40 years. The second assumption is that the owner prefers to plan periodic actions of replacement (here 5 and 10 years) to allocate the costs periodically and simplify the management (Note that some authors have shown that the optimal cost is not obtained with this type of strategy; Breysse et al., 2007; Sheils et al., 2007; Breysse et al., 2009). The reference period $t_{\text {end }}$ is 70 years. The following numerical experimental plan has been programmed.
Ten strategies based on regularly spaced replacement are compared:

- strategy S11: no replacement before 20 years, periodic replacement every 5 years until 70 years;

- strategy S12: no replacement before 20 years, periodic replacement every 10 years until 70 years;

- strategy S21: no replacement before 25 years, periodic replacement every 5 years until 70 years;

- strategy S22: no replacement before 25 years, periodic replacement every 10 years until 70 years;

- strategy S31: no replacement before 30 years, periodic replacement every 5 years until 70 years;

- strategy S32: no replacement before 30 years, periodic replacement every 10 years until 70 years;

- strategy S41: no replacement before 35 years, periodic replacement every 5 years until 70 years;

- strategy S42: no replacement before 35 years, periodic replacement every 10 years until 70 years;

- strategy S51: no replacement before 40 years, periodic replacement every 5 years until 70 years; and

- strategy S52: no replacement before 40 years, periodic replacement every 10 years until 70 years.

The confidence levels at $5 \%$ and $95 \%$ on the number of failed RCPs are considered to illustrate the scatter on this number. Figure 7 illustrates the updated curves for RCPs in singular areas obtained for the strategy S32 with five dates of replacement. Note that in this case, the maximum number of failed RCPs is 90: the total number of RCPs in singular areas. A similar curve is obtained for RCPs in ordinary areas. 


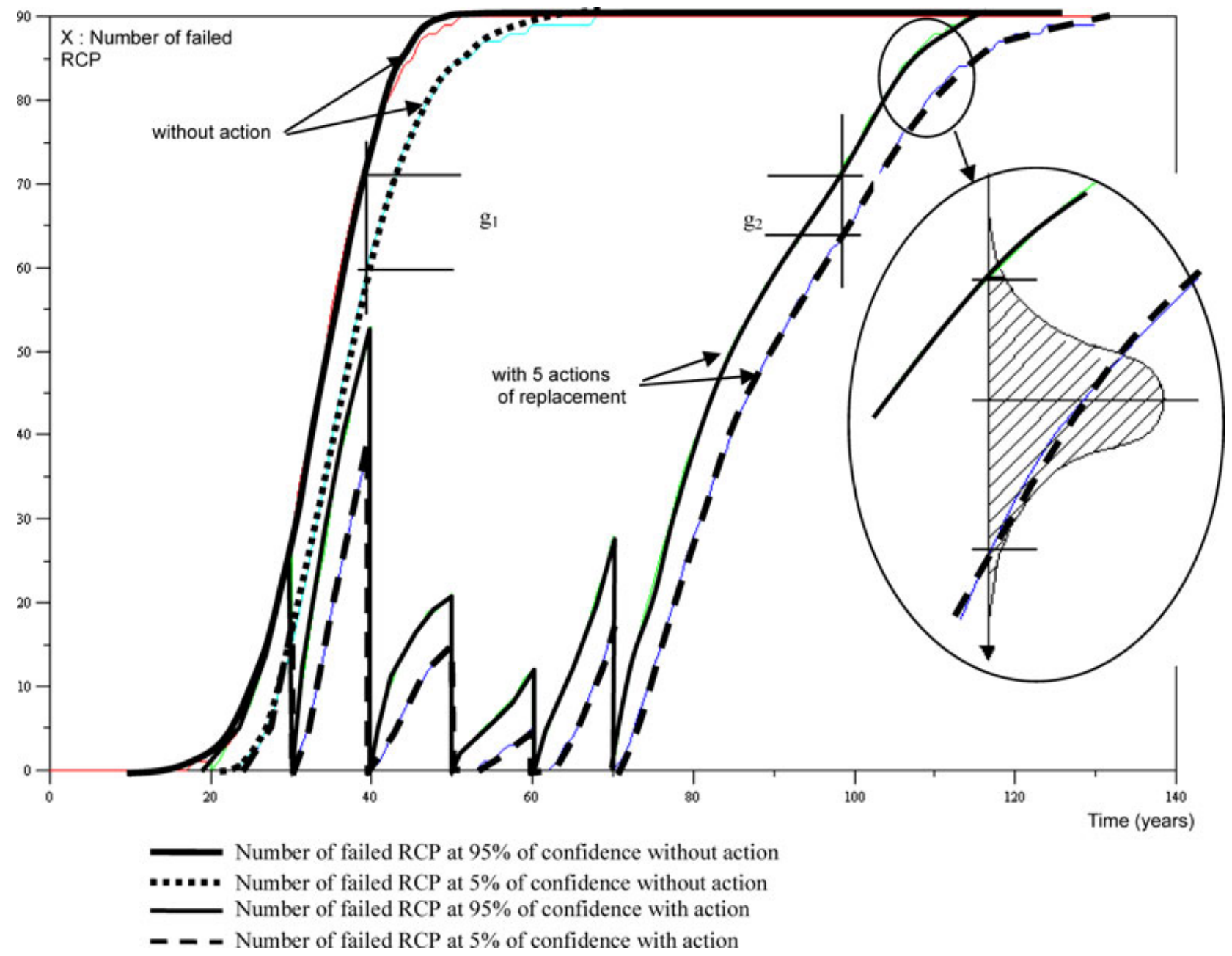

Fig. 7. Evolution of the number of failed RCPs in singular areas (curves at $5 \%$ and $95 \%$ level of confidence) after five actions at times $30,40,50,60$, and 70 years.

The result shows that this type of strategy drastically reduces the gradient of the plot of the number of failed RCPs with time and thus the expected lifetime. This influence is significant around 55 years. It can be explained by the fact that after four actions of replacement, a large amount of RCPs (87) have been replaced, which represents about $30 \%$ of the network. The time needed to reach a totally failed RCP network is increased, after actions of replacement, from 50 years to 110 years. It is interesting to compare the curves at $5 \%$ and $95 \%$ level of confidence. It appears that the gap between these curves is greater before maintenance ( $g_{1}$ in Figure 7) than after replacements $\left(g_{2}\right)$. The number of $\mathrm{RCP}$ replacements with time, in singular and ordinary areas, is computed and is given in Table 2. The scatter of the number of potential replacements can be analyzed through the interval of confidence (5\% and $95 \%)$. The range of this interval is $13,13,6$, and 7 , respectively, after $2,3,4$, and 5 repair actions. As replacement actions modify the initial population by introducing new RCPs, the standard deviation of the number of failed RCPs decreases after three maintenance actions compared with the one obtained without any action. It is particularly significant at 60 years.

Table 2

Results obtained for the strategy based on fixed dates (S12)

\begin{tabular}{lccc}
\hline & $\begin{array}{c}\text { Number of } \\
\text { replaced } \\
\text { RCPs (5\% }\end{array}$ & $\begin{array}{c}\text { Number of } \\
\text { replaced } \\
\text { RCPs (maximum } \\
\text { likelihood) }\end{array}$ & $\begin{array}{c}\text { Number of } \\
\text { replaced } \\
\text { replacement }\end{array}$ \\
\hline confidence) & confidence) \\
20 & 0 & 1 & 1 \\
30 & 15 & 21 & 28 \\
40 & 40 & 47 & 53 \\
50 & 15 & 18 & 21 \\
60 & 5 & 9 & 12 \\
70 & 17 & 22 & 28 \\
\hline
\end{tabular}


Table 3

Number of replaced RCPs in ordinary and special areas for the 10 strategies

\begin{tabular}{|c|c|c|c|c|c|c|c|c|c|c|c|c|c|c|c|c|c|c|c|}
\hline \multicolumn{2}{|c|}{$S 11$} & \multicolumn{2}{|c|}{$S 12$} & \multicolumn{2}{|c|}{$S 21$} & \multicolumn{2}{|c|}{$S 22$} & \multicolumn{2}{|c|}{$S 31$} & \multicolumn{2}{|c|}{$S 32$} & \multicolumn{2}{|c|}{$S 41$} & \multicolumn{2}{|c|}{$S 42$} & \multicolumn{2}{|c|}{ S51 } & \multicolumn{2}{|c|}{ S52 } \\
\hline 20 & 1 & 20 & 1 & & & & & & & & & & & & & & & & \\
\hline 25 & 4 & & & 25 & 5 & 25 & 5 & & & & & & & & & & & & \\
\hline 30 & 16 & 30 & 21 & 30 & 16 & & & 30 & 22 & 30 & 22 & & & & & & & & \\
\hline 35 & 25 & & & 35 & 25 & 35 & 42 & 35 & 25 & & & 35 & 46 & 35 & 47 & & & & \\
\hline 50 & 6 & 50 & 18 & 50 & 6 & & & 50 & 6 & 50 & 18 & 50 & 10 & & & 50 & 6 & 50 & 18 \\
\hline 55 & 2 & & & 55 & 3 & 55 & 9 & 55 & 3 & & & 55 & 17 & 55 & 8 & 55 & 2 & & \\
\hline 60 & 6 & 60 & 9 & 60 & 6 & & & 60 & 6 & 60 & 8 & 60 & 47 & & & 60 & 1 & 60 & 3 \\
\hline 65 & 12 & & & 65 & 11 & 65 & 14 & 65 & 11 & & & 65 & 21 & 65 & 12 & 65 & 3 & & \\
\hline 70 & 16 & 70 & 22 & 70 & 16 & & & 70 & 16 & 70 & 23 & 70 & 13 & & & 70 & 13 & 70 & 16 \\
\hline
\end{tabular}

$d=$ date of replacement; $n=$ number of replaced RCPs at each date; $T=$ total number of replaced RCPs.

Overall results obtained for the 10 strategies are given in Table 3. The replacements concern both ordinary and singular areas.

We notice that the number of replaced RCPs is very close for the first seven strategies except for strategy S22. For the remaining strategies, the total number of replacements decreases. The number of failed RCPs at the first date of replacement is then very high, and serviceability considerations could be not respected. From results obtained with strategies S12, S21, and S41, we presume that the optimum could be obtained with a first replacement between 26 and 34 years (except 30 years to avoid replacement at 70 years). Note that Tables 2 and 3 cannot already answer the question: "what is the Best Maintenance Strategy of those selected?" because as yet no serviceability constraint has been introduced. Cost and maintenance constraints are introduced at the end of this article.

Another point of interest is the comparison of the number of replaced RCPs in both types of areas (ordinary and singular areas). The evolution of the ratio "replaced RCP in singular areas/replaced RCP in ordinary areas" is thus of interest. The evolution of this ratio for the strategies involving replacement every 5 years (S11, S21, S31, S41, and S51) is plotted in Figure 8. Note that it is interesting to compare this rate with the ratio "special areas/ordinary areas," which is 39\% (dashed line in Figure 8). RCPs located in singular areas are replaced first and represent more than $50 \%$ of the replaced RCPs, whatever be the policy: this rate remains between $75 \%$ and $100 \%$ for replacements carried out between 25 and 32 years. Then, when studying the first 70 years, this population has been totally renewed dur- ing the first years of maintenance, and no intervention is required after a given time around 55 years. The more the initial replacement is postponed, the lower is the rate, because a higher number of other RCPs start to deteriorate.

\subsection{Upper-bound value for the number of failed RCPs}

A serviceability constraint is introduced at this point. The target for maintenance policy is "to keep the number of deteriorated components (i.e., the number corresponding to the maximum likelihood) under a limit value considered as acceptable." This strategy is equivalent to the one that requires a limit leakage, for example. To illustrate the sensitivity of this strategy to the acceptable level, four values of acceptable number of failed RCPs are studied: they are expressed as a percentage of the total number of RCPs. The considered strategies are:

- strategy $S^{\prime} 1$ : threshold fixed at $15 \%$ of the number of RCPs in ordinary areas,

- strategy $\mathrm{S}^{\prime} 2$ : threshold fixed at $20 \%$ of the total number of RCPs in ordinary areas,

- strategy S'3: threshold fixed at $40 \%$ of the total number of RCPs in ordinary areas, and

- strategy S'4: threshold fixed at $50 \%$ of the total number of RCPs in ordinary areas.

Figures 9 and 10 present the evolutions of the bounds of confidence interval (5\% and $95 \%$ ) of the number of failed RCPs with time. Let us focus first on the results illustrated by Figure 9 obtained with the strategy $\mathrm{S}^{\prime} 2$ for RCP in ordinary areas with a threshold fixed at $20 \%$ (i.e., 28 RCPs among 138). Note that the curve 


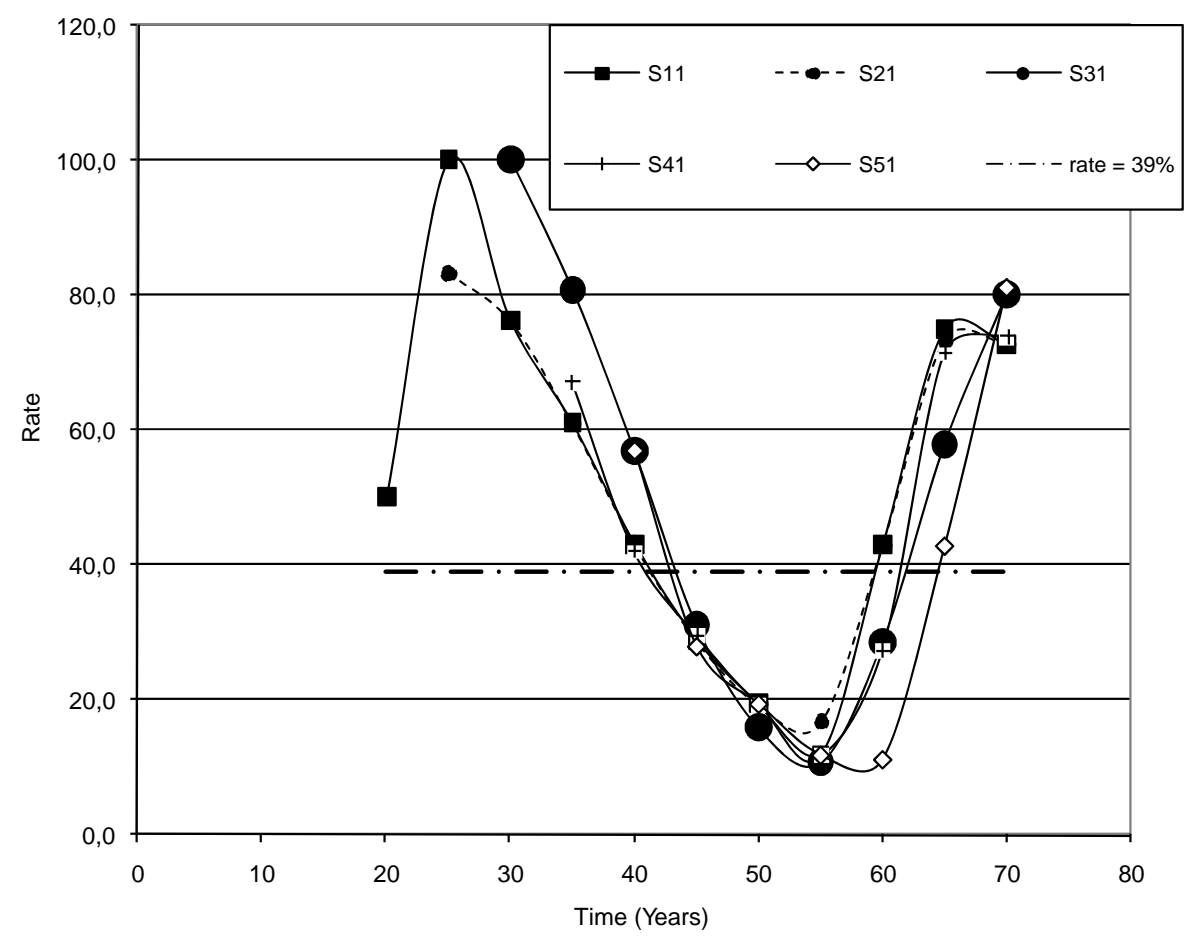

Fig. 8. Evolution of the rate of replaced RCPs located in special areas.

corresponding to the upper bound of the confidence interval (i.e., 95\%) does not respect the threshold because the replacement is governed by the number of replaced RCPs corresponding to the maximum likelihood (Table 2). The two curves at the left-hand side correspond to "reference curves" that represent the case with no action (no replacement). It is interesting to underline that after four actions, a lot of segments have been replaced, and the gradient of the graph is very small around 65 years. We represent the evolution after 70 years, even if the criterion is not respected (values exceed the threshold), to illustrate this point. This very fair evolution is more visible in Figure 10 for the strategy $\mathrm{S}^{\prime} 4$ : threshold equals 69 . The number of deteriorated pipes is then quite constant during 5 years from 60 to 65 years. The conclusions made previously on the difference between the confidence curves at $5 \%$ and $95 \%$ are similar.

We can conclude that the acceptable level of failure has a great influence on the number of replacements. In terms of cost analysis, another constraint must be included: the discount rate, which makes a postponed replacement more expensive. Note that Table 4 cannot already answer the question: "what is the Best Maintenance Strategy of those selected?" because no consequences of action or inaction were introduced. The cost and maintenance constraints are introduced to this aim in the following section.

\section{COST ANALYSIS OF MAINTENANCE STRATEGIES}

\subsection{Cost assumptions}

The objective here is to find the strategy that leads to the minimal cost. This approach is an alternative to the multicriteria analysis (Le Gauffre et al., 2007). In terms of cost, the number of operations and the number of RCP replacements should be introduced. In fact, the former implies stopping system utilization, and the latter the procurement and installation of new RCPs (including the cost of replacing deteriorated pipes). Failure costs, meaning financial consequences of failure, are not taken into account in this example, but are included in the software SIMEO ${ }^{\mathrm{TM}}$ Manager (Oxand's internal software; OXAND, Avon, France). The reason of this choice by the others is to focus on the effect of inspection and repair costs on the strategies. In fact, for nuclear stations, failure costs are difficult to assess with accuracy because they depend on the limit of the system (owner, society, etc.) 


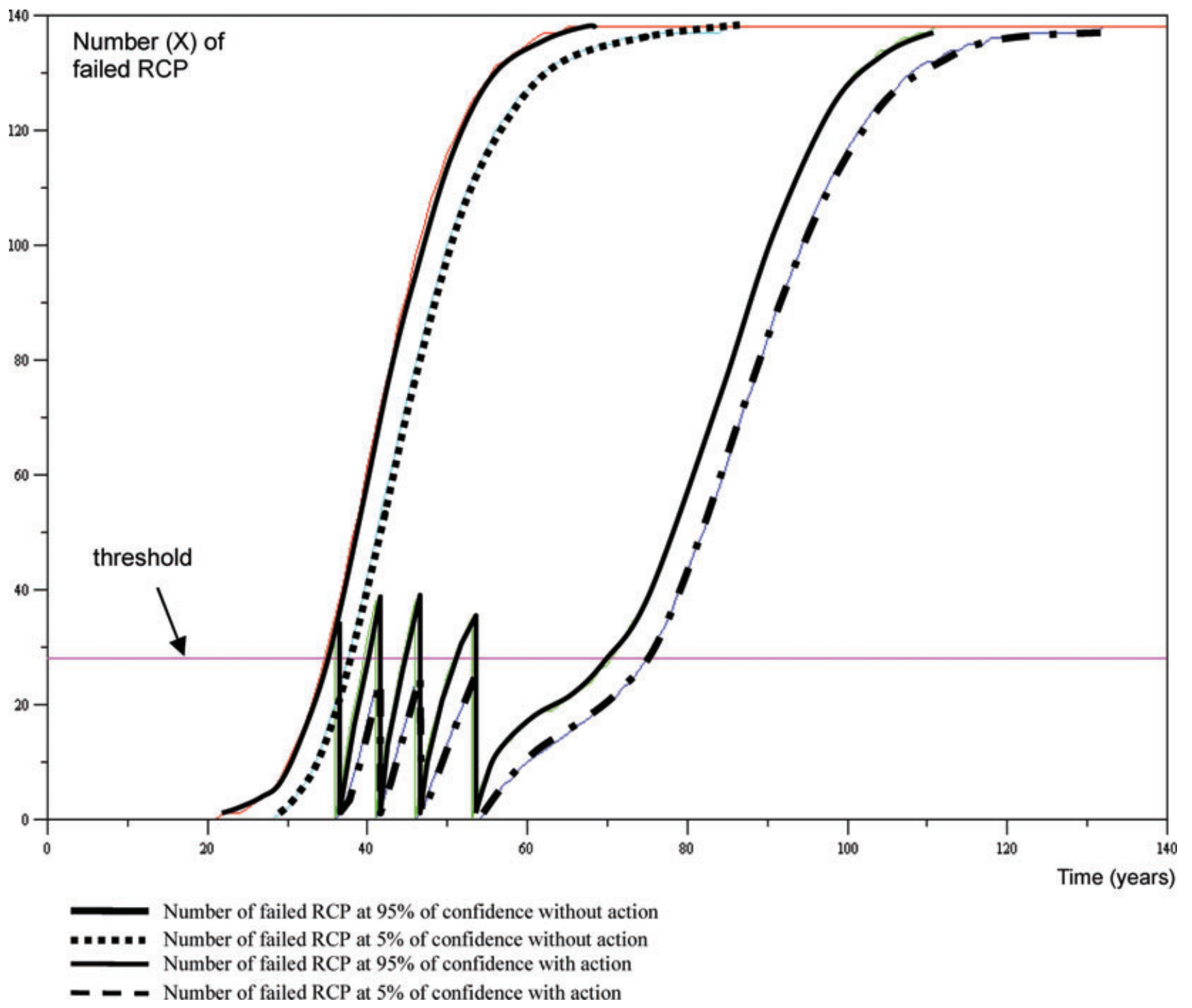

Fig. 9. Evolution of the number of failed RCPs in ordinary areas (curves at $5 \%$ and $95 \%$ level of confidence) after four actions. Acceptable number of failed components $=20 \%$.

and the estimation and aggregation of indirect costs. In this case, the failure cost is a stochastic process itself and requires deeper investigation to be defined precisely. The following hypotheses and constraints are considered:

- The pumping network is stopped once a year, and no costs arise from this break in operation. During this time, $30 \mathrm{~m}$ can be removed.

- For the removal of longer sections of the RCP network, it is considered that every $5 \mathrm{~m}$ requires a 1-day break in operation, which incurs a cost of 30,490 Euros (because of the loss of services).

- The replacement of $6 \mathrm{~m}$ costs 25,556 Euros;
- The discount rate of money is $8 \%$.

- It is considered that failed areas are on distinct RCPs, and that a whole RCP of 1-m length must be replaced in the case of corrosion.

Note that several assumptions can be selected and are directly linked with the commercial and financial stakes and functions of the structures (Kenné et al., 2007) and the supply of human resources (Martorell et al., 2007b). Figure 11 represents the costs obtained for the strategies presented in the previous section. Strategies with a periodic replacement are more expensive, in particular, strategies S12, S32, and S52. It is more cost-effective to renew often (5 years). The strategies planned using an 


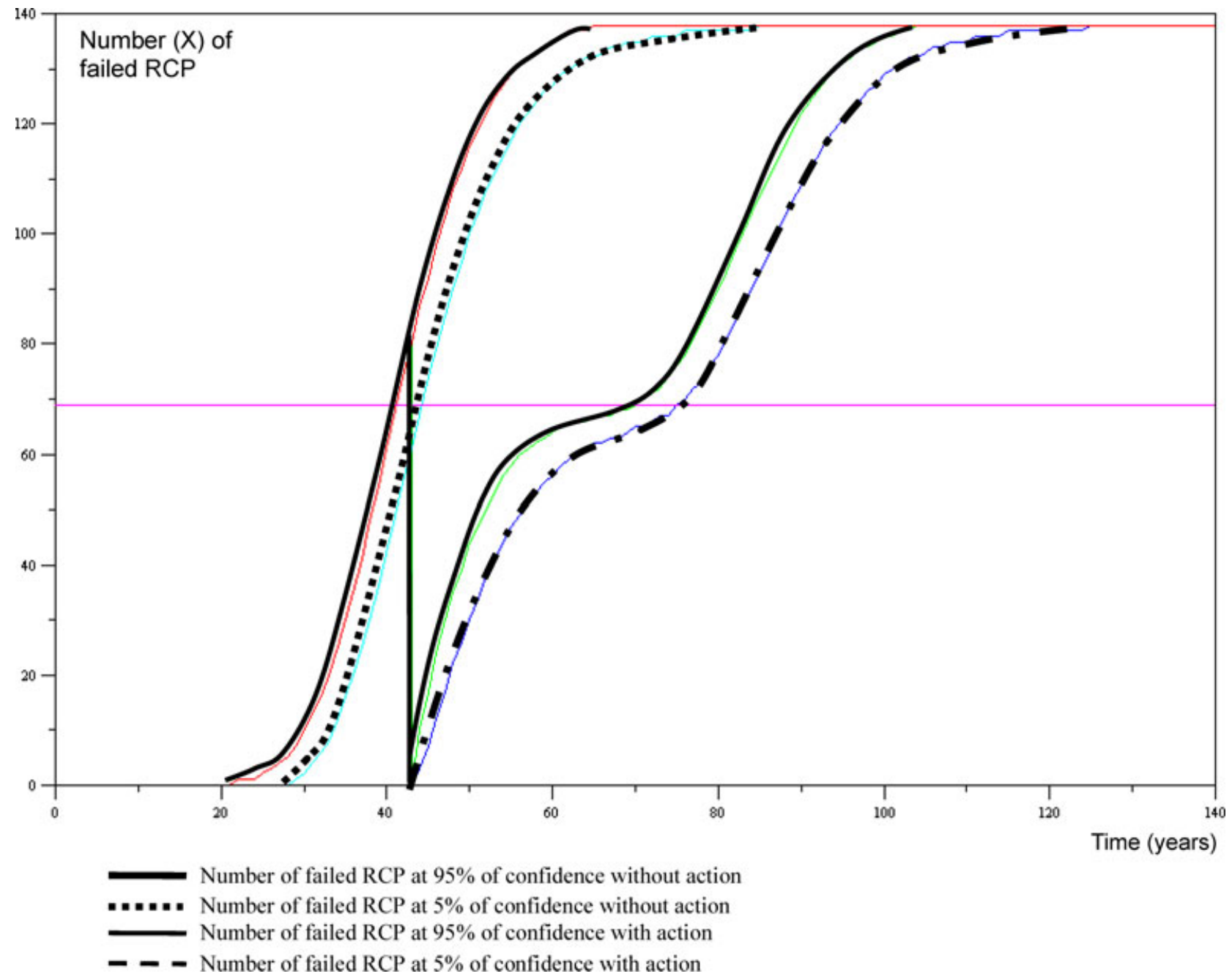

Fig. 10. Evolution of the number of failed RCPs in ordinary areas (curves at $5 \%$ and $95 \%$ level of confidence) after one action. Acceptable number of failed components $=50 \%$.

acceptable level of failed RCPs are less expensive, with the levels considered here.

It is now interesting to analyze the uncertainty of the number of replaced RCPs, which varies depending

Table 4

Number of replaced RCPs for the four strategies

\begin{tabular}{|c|c|c|c|c|c|c|c|}
\hline \multicolumn{2}{|c|}{$S^{\prime} 1$} & \multicolumn{2}{|c|}{$S^{\prime} 2$} & \multicolumn{2}{|c|}{$S^{\prime} 3$} & \multicolumn{2}{|c|}{$S^{\prime} 4$} \\
\hline$d$ & $n$ & $d$ & $n$ & $d$ & $n$ & $d$ & $n$ \\
\hline 36 & 28 & & & & & & \\
\hline 41 & 30 & 39 & 46 & 41 & 58 & 43 & 71 \\
\hline 46 & 31 & 46 & 43 & 52 & 57 & & \\
\hline 53 & 29 & 59 & 42 & & & & \\
\hline$T$ & 118 & & 131 & & 115 & & 71 \\
\hline
\end{tabular}

$d=$ date of replacement; $n=$ number of replaced RCPs at each date;

$T=$ total number of replaced RCPs. on the strategy considered. After maintenance, some strategies lead to a very heterogeneous set of RCPs, whereas others lead to a homogeneous set of RCPs. This result is closely linked to the values $g_{1}$ and $g_{2}$ presented in Figure 7. We can now introduce a risk of extra cost because of a number of replaced RCPs calculated on the basis of the confidence value at $95 \%$. Figure 12 presents the costs for strategies S21 and S51, which are shown to be the less expensive periodic policies on Figure 11. S21 and S51 are very close in terms of total cost, but the risk of overcost for the former is twice that of the latter.

At the beginning of this article, the problem of cdf fitting was discussed (Figure 3). Figure 13 illustrates this point on the basis of the cdf given in Figure 3 and a set of 228 RCPs of 1-m length. A sensitivity analysis is made on the number and the cost. The results are, of course, similar. The programmed strategy is a replacement 


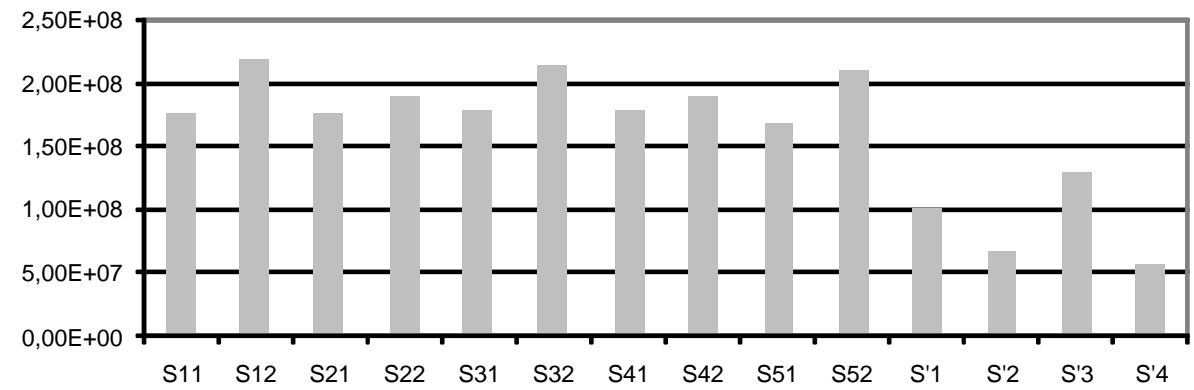

Fig. 11. Total cost of the overall set of strategies.

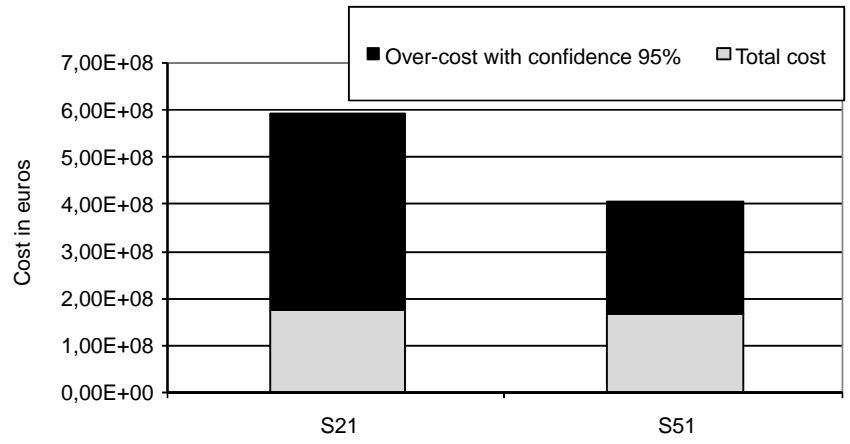

Fig. 12. Comparison of the level of total costs and overcosts for strategies S21 and S51.

every 4 years after the network has been in service for 10 years. The difference between two fitted cdfs (normal and gumbel) can reach $25 \%$ for the number of RCPs and $24 \%$ for the costs after 22 years. This difference is because of the fact that mainly the beginning of the curve-which fits better than the latter section-is concerned.

\section{CONCLUSION}

This article provides a theoretical approach to analyze alternative strategies for the management of a RCP network. It is based on (1) the results of a reliability study, (2) the use of random draws (binomial probability distribution), and (3) the decision tree representation to define maintenance scenarios. This method provides an estimation of the evolution of the number of deteriorated RCPs with a confidence level. The curves at 5\% and $95 \%$ confidence levels are computed and plotted. Two strategies are compared: (1) the date on which actions are undertaken, and (2) the total number of failed RCPs is limited to a threshold. Finally, a cost study is proposed and it shows how to include costs in such a maintenance strategy. The notion of overcost risk is presented as a new criterion for strategy comparison. Finally, one must take care in selecting the original cdf for the fitting, as it can lead to great errors in terms of cost evaluation.

Note that this approach provides an efficient way to predict a decision, assuming that it will be based on

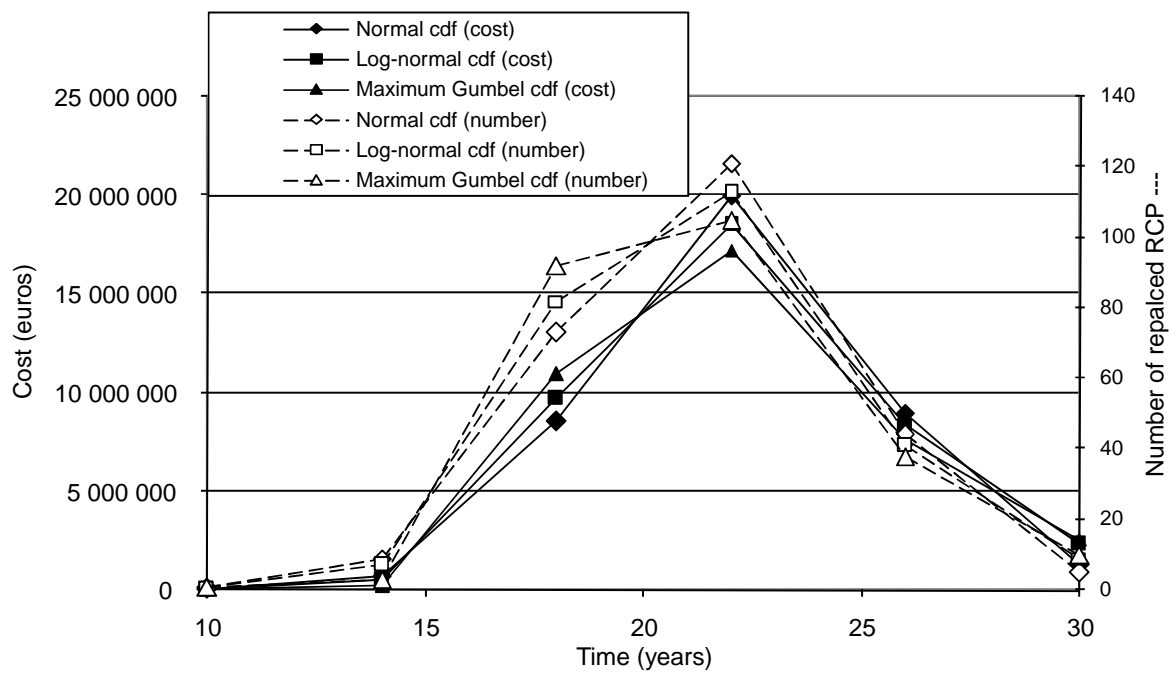

Fig. 13. Sensitivity of cost and the number of replaced RCPs to cdf selection. 
the maximum likelihood of the distribution of failed RCPs. By knowing the probability of detection or the probability of false alarm, it can be linked to a riskbased inspection plan. In this case, the decisions of repair and inspection are generally made at the same time. Thus, in our approach, only the possible number of replaced RCPs will change. This method has been implemented in SIMEO-Manager software: it offers a whole customer-oriented package for analyzing maintenance strategies.

\section{ACKNOWLEDGMENTS}

The authors gratefully acknowledge Dr. Antoine Rouhan, Dr. Kefei Li, and Yoann Lahorgue for their helpful contributions to this work.

\section{REFERENCES}

Adey, B., Bernard, O. \& Gérard, B. (2003), Risk-based replacement strategies for underground reinforced concrete pipe networks, in 2nd International Rilem Workshop on Life Prediction and Ageing Management of Concrete Structures, Paris, France, May 5-6.

Andrade, C. (2004), Calculation of initiation and propagation periods of service-life of reinforcements by using the electrical resistivity, in International Symposium on Advances in Concrete through Science and Engineering, RILEM Symposium, Evanston, IL, March 22-24.

Bjørnøy, O. H., Jahre-Nilsen, C., Eriksen, Ø. \& Mørk, K. (2001), RBI planning for pipelines, description of approach, in Proceedings of OMAE'01, 20th International Conference on Offshore Mechanics and Arctic Engineering, no. OMAE2001/PIPE-4008, Rio de Janeiro, Brazil, June 3-8.

Breysse, D., Elachaci, S. M., Sheils, E., Schoefs, F. \& O'Connor, A. (2009), Life cycle cost analysis of ageing structural components based on non destructive condition assessment, Australian Journal of Structural Engineering, Special Issue "Disaster \& Hazard Mitigation", 9(1), 55-66.

Breysse, D., Vasconcelos, E. \& Schoefs, F. (2007), Management strategies and improvement of performances of sewer networks, Computer Aided Civil and Infrastructure Engineering, 22(7), 462-77.

Cambridge Systematics (1997), Pontis Release 3.2-Users Manual, American Association of State Highway and Transportation Officials, Inc., Washington, DC.

Carlos, S., Martorell, S., Villanueva, J. F., Serradell, V. \& Sánchez, A. (2007), A multi-objective genetic algorithm for RAMS $+\mathrm{C}$ optimization with uncertain decision variables, in Proceedings of the ESREL Conference, June 25-27, Stavanger, Norway.

Collepardi, M. (1997), Quick method to determine free and bound chlorides in concrete, in L. O. Nilsson \& J. P. Ollivier (eds.), in Proceedings of the 1st International Rilem Workshop "Chloride Penetration into Concrete", Saint-Rémylès-Chevreuse, France, October 15-18. RILEM, Cachan, France, 1997, pp. 10-16.
De Melo, A. C. V. \& De J. Sanchez, A. (2005), Bayesian networks in software maintenance management, Lecture Notes in Computer Science. SOFSEM 2005: Theory and Practice of Computer Science, Book, Vol. 3381/2005, pp. 394-98, Springer, Berlin/Heidelberg Ed.

Dridi, L., Parizeau, M., Mailhot, A. \& Villeneuve, J. P. (2008), Using evolutionary optimization techniques for scheduling water pipe renewal considering a short planning horizon, Computer Aided Civil and Infrastructure Engineering, 23(8), 625-35.

Estes, A. C. \& Frangopol, D. M. (2001), Minimum expected cost-oriented optimal maintenance planning for deteriorating structures: Application to concrete bridge decks. Reliability Engineering and System Safety, 73, 281-91.

Faber, M. H. \& Sorensen, J. D. (2002), Indicators for inspection and maintenance planning of concrete structures, Structural Safety, 24, 377-96.

Frederiksen, J. M., Nilsson, L. O., Sandberg, P., Poulsen, E., Tang, L. \& Andersen, A. (1997), Hetek, a system for estimation of chloride ingress into concrete: Theoretical background, Road Directorate, Denmark Ministry of Transport, report no. 83, 118 pp.

Hendawi, S. \& Frangopol, D. (1994), System reliability and redundancy in structural design and evaluation. Structural Safety, 16, 47-71.

Kenné, J.-P., Gharbi, A. \& Beit, M. (2007), Age-dependent production planning and maintenance strategies in unreliable manufacturing systems with lost sale, European Journal of Operational Research, 178(2), 408-20.

Le Gauffre, P., Haidar, H., Poinard, D., Laffrechine, K., Baur, R. \& Schiatti, M., (2007), A multicriteria decision support methodology for annual rehabilitation programs of water networks, Computer-Aided Civil and Infrastructure Engineering, 22(7), 478-88.

Li, C.-Q., Ian Mackie, R. \& Lawanwisut, W. (2007), A riskcost optimized maintenance strategy for corrosion-affected concrete structures, Computer-Aided Civil and Infrastructure Engineering, 22(5), 335-46.

Li, D. \& Haimes, Y. Y. (1992), Optimal maintenance related decision making for deteriorating water distribution systems 1. Semi-Markovian model for a water main, Water Resources Research 28(4), 1053-61.

Luong, H. T. \& Fujiwara, O. (2002), Fund allocation for pipe repair maintenance in water distribution networks, European Journal of Operational Research 136, 403-21.

Marchand, J., Samson, E., Maltais, Y., Lee, R. J. \& Sahu, S. (2002), Predicting the performance of concrete structures exposed to chemically aggressive environment. Field validation, Materials and Structures, 35(10), 2002, 623-31.

Martorell, S., Sanchez, A. \& Carlos, S. (2007a), A tolerance interval based approach to address uncertainty for RAMS+C optimization, Reliability Engineering and System Safety, 92(4), 408-22.

Martorell, S., Sánchez, A., Carlos, S. \& Serradell, V. (2004), Alternatives and challenges in optimizing industrial safety using genetic algorithms, Reliability Engineering and System Safety, 86(1), 25-38.

Martorell, S., Sánchez, A., Villamizar, M. \& Clemente G. (2007b), Maintenance modelling and optimization integrating strategies and human resources, in Proceedings of the ESREL Conference, June 25-27, Stavanger, Norway.

Micevski, T., Kuczera, G. \& Coombes, P. (2002), Markov model for storm water pipe deterioration, Journal of Infrastructure Systems 8(2), 49-56. 
Miyamoto, A., Kawamura, K. \& Nakamura, H. (2001), Development of a bridge management system for existing bridges, Advances in Engineering Software, 32, 82133.

Mori, Y. \& Ellingwood, B. (1994a), Maintenance reliability of concrete structures I: Role of inspection/repair, Journal of Structural Engineering, 120(3), 824-45.

Mori, Y. \& Ellingwood, B. (1994b), Maintenance reliability of concrete structures II: Optimum inspection/repair, Journal of Structural Engineering, 120(3), 846-62.

Nilsson, L. O. (2000), On the uncertainty of service-life models for reinforced marine concrete structures, in Proceedings of the International RILEM Workshop Life Prediction and Age Management of Concrete Structures, Cannes, France, October 16-17.

Nunes, L. M., Paralta, E., Cunha, M. C. \& Ribeiro L. (2007), Comparison of variance-reduction and space-filling approaches for the design of environmental monitoring networks, Computer Aided Civil and Infrastructure Engineering, 22(7), 489-98.

Onofriou, T. \& Frangopol, D. M. (2002), Reliability-based inspection optimisation of complex structures: A brief retrospective, Computers and Structures, 80, 1133-44.

Pakrashi V., Schoefs F., Memet, J. B. \& O'Connor, A. (2008), An image analysis based damage classification methodology, Structure and Infrastructure Engineering: Maintenance, Management, Life-Cycle Design and Performance (NSIE). First published April 30, 2008, doi: dx.doi.org/10.1080/15732470701718072.

Peter-Lazar, I., Heinfling, G., Gerard, B. \& Marchand, J. (2000), Application of probabilistic methods to the analysis of the behaviour of reinforced concrete structures affected by steel corrosion, in Proceedings of CANMET Conference "Concrete durability", Barcelona, Spain, June 4-9, 2000, pp. 557-72.

Ritchie, D., Voermans, C. W. M., Larsen, M. H. \& Vranckx, W. R. (1998), Probabilistic tools for planning of inspection and repair of corroded pipelines, in Proceedings of OMAE'98, 17th International Conference on Offshore Mechanics and Arctic Engineering, July 5-9, 1998, Lisbon, Portugal, no. OMAE98-0901.

Roelfstra, G. (2001), A model of condition evolution of concrete highway bridges (in French), Ph.D. thesis 2310,
The Swiss Federal Institute of Technology, Lausanne, Switzerland.

Rouhan, A. \& Schoefs, F. (2003), Probabilistic modelling of inspection results for offshore structures, Structural Safety, 25(4), 379-99.

Sánchez, A., Martínez-Alzamora, N., Mullor, R. \& Martorell, S. (2007), Motor-operated valve maintenance optimization considering multiple failure modes and imperfect maintenance models, in Proceedings of the ESREL Conference, June 25-27, Stavanger, Norway.

Sarma, K. C. \& Adeli, H. (2002), Life-cycle cost optimization of steel structures, International Journal for Numerical Methods in Engineering, 55(12), 1451-62.

Schoefs, F. (2009), Risk analysis of structures in presence of stochastic fields of deterioration: Coupling of inspection and structural reliability, Australian Journal of Structural Engineering, Special Issue "Disaster \& Hazard Mitigation", 9(1), 67-78.

SCILAB (2007), Scilab 4.1.2: The open source platform for numerical computation. Scilab Consortium, INRIA. Available at: http://www.scilab.org, accessed April 2009.

Sheils, E., Schoefs, F., Breysse, D. \& O'Connor, A. (2007), Comparing efficiency of systematic and conditional maintenance for randomly ageing components, in Proceeding of 10th International Conference on Applications of Statistics and Probability in Civil Engineering, (I.C.A.S.P'07), July 31-August 3, The University of Tokyo, Kashiwa Campus, Tokyo, Japan.

Sheils, E., O’Connor, A., Breysse, D., Schoefs, F. \& Yotte, S. (2008), Development of a two stage inspection process for the assessment of deteriorating bridge structures. Reliability Engineering and Structural Safety, in press.

SIMEO $^{\mathrm{TM}}$ (2006), Simulator to study concrete and steel ageing in normal ageing conditions or in an accelerated ageing process. Available at: http://www.simeo-erm.com, accessed April 2009.

Tang, L. (1996), Chloride transport in concrete-measurement and prediction, Ph.D. thesis, Chalmers University of Technology, Gotheborg, Sweden.

Truc, O. (2000), Prediction of chloride penetration into saturated concrete. Multi-species approach, Ph.D. thesis, Chalmers University, Göteborg, Sweden; Institut National des Sciences Appliquées, Toulouse, France, 173 pp. 